\title{
Incentives, health promotion and equality
}

\section{Kristin Voigt}

Final version published in Health Economics, Policy and Law 2012, 7(3), 263-283.

\section{Introduction}

An increasingly popular strategy in health policy is the use of 'incentives' to encourage individuals to avoid health risks such as smoking and to adopt beneficial health behaviours such as physical activity and participation in cancer screening programmes. Such schemes offer a specified benefit or threaten to withdraw such a benefit, depending on whether or not individuals meet particular requirements. Much of the literature has been highly critical of policies that involve 'negative' incentives, often on grounds of fairness and social justice. 'Positive' incentives, on the other hand, which are to support individuals in improving their health behaviours, have generally been welcomed as an important instrument for the improvement of population health and possibly even the reduction of health inequalities; ${ }^{2}$ at the same time, a possible conflict with equity considerations is sometimes noted. ${ }^{3}$

The aim of this paper is to assess incentive schemes from the perspective of equality. In particular, I will consider the problems and possible benefits of incentive schemes along two important dimensions of equality: equality of access and equality of outcome. As will be apparent in this discussion, the extent to which incentive schemes come into conflict with equality and whether or not they can help reduce health inequalities depends, ultimately, on empirical facts; the aim of this paper is to point to various problems we should be aware of and empirical questions we need to ask in order to determine whether a specific incentive scheme is consistent with, or possibly even conducive to, (health) equality.

The paper proceeds as follows. In section 2, I describe a range of incentive schemes that have been used or proposed to improve individuals' health behaviours. The schemes vary widely with respect to who implements and monitors them, the targeted health behaviours, the populations to which they apply and the kinds of incentives provided. Section 3 considers the distinction between positive and negative incentives - or 'carrots' and 'sticks' - on which commentators often draw in evaluating incentive schemes. I raise concerns about the ease with which the distinction is usually drawn in the literature and suggest that, while this distinction may point to some important differences among incentive schemes, even policies we might describe as 'carrots' can be problematic from the perspective of equality. Section 4 sets out the framework used to evaluate incentive schemes in this paper. While, in section 5, the discussion focuses on issues concerning equal access, both with respect to the benefits provided by incentive schemes and different health behaviours, section 6 considers the effects that incentive schemes may have on outcome inequalities. Section 7 describes some caveats and trade-offs relevant to the overall evaluation of incentive schemes. Section 8 concludes.

\section{Incentives in practice: an overview}

In a wide range of policies, incentives have been used with a view to changing individual health 
behaviours. This section provides an overview of the different kinds of policies that have been proposed or implemented in different countries.

Different agents have used incentives to affect individuals' behaviour. In the US, many policies have been put in place as part of employer-based insurance plans. ${ }^{4}$ For example, companies may offer reimbursements for the cost of gym memberships, or reductions in insurance premiums, copayments or deductibles for employees who do not smoke. Incentive programmes have also been implemented by private health insurers. For example, sickness funds in Germany provide a variety of benefits, ranging from lower co-payments to MP3-players, for members who participate in screening, fitness or weight loss programmes. ${ }^{5}$ Finally, the UK National Health Service recently introduced a pilot programme entitled 'Pounds for Pounds', where participants can receive cash upon achieving and maintaining weight loss. ${ }^{6}$ Furthermore, different agents may be involved in administering the schemes. Many incentive schemes require health professionals to confirm that specific conditions are met and to determine whether or not specific goals are suitable for individual patients given existing medical conditions (Bishop and Brodkey, 2006).

We can also distinguish between different policies on the basis of the range of individuals to whom they apply. Some incentive schemes apply to all citizens of a country, whereas others would affect only a specific section of the population. An important question with respect to incentive schemes that are available only to a subset of a particular population is whether eligible individuals are of roughly similar or of different levels of advantage. For example, incentives offered by German sickness funds generally apply to a group of individuals from very different socio-economic backgrounds, whereas an incentive scheme put in place as part of a Medicaid initiative would apply to a low-income group. Similarly, some incentive schemes apply only to patients with specific health problems; e.g., clinicians in the UK have experimented with the use of incentives for psychiatric patients who comply with anti-psychotic depot medication (Claassen et al., 2007; Claassen, 2007).

Some schemes also require parents to meet conditions that are meant to benefit the health of their children, for example by offering a cash benefit to parents whose children have all age-appropriate vaccinations. Conditional cash transfer schemes in developing countries often include conditions of this kind (see, e.g., Lagarde et al., 2007), and this approach has also been used in the US (McColl, 2008; Kerpelman et al., 2000).

Incentives have been introduced to reward or penalise a wide range of behaviours. Many policies aim to make individuals abstain from 'unhealthy' behaviour such as smoking, and/or encourage them to make 'healthy' choices, such as exercising or learning a relaxation technique. Some policies aim at patients' compliance with doctors' advice and prescribed medication (Schmidt, 2008; Claassen, 2007; Claassen et al., 2007), getting vaccinations and regular check-ups, and taking up screening services. ${ }^{7}$ Some sickness funds also offer discounts to enrolees for years in which they are not admitted to hospital or prescribed medication by a doctor. ${ }^{8}$ One scheme also considered whether or not individuals had taken out health insurance (McColl, 2008).

One important distinction to draw here is between incentive schemes that reward individuals for attempting to change a certain behaviour and those that make the reward conditional on an individual's success in changing that behaviour, either by reaching a specific goal or by making progress towards that goal. This distinction is borne out most clearly in the US context, where current legislation distinguishes between schemes that reward individuals for participating in a wellness programme, such as a weight loss or smoking cessation class, and those that tie the reward to the attainment of particular goals, such as body mass index within a specified range or non- 
smoking status (Federal Register, 2006; Mello and Rosenthal, 2008; Schmidt et al., 2009b). In addition, when employees succeed in losing weight but remain over-weight, an employer might, for example, accept a 10 per cent reduction in body mass index as satisfying the weight requirement. These differences may, of course, give rise to very different normative assessments.

Finally, incentives can be provided in a variety of different 'currencies'. Some policies provide incentives in the form of cash, e.g. by lowering premiums, co-pays or deductibles for individuals who meet the stated requirements. Other policies, such as the German 'bonus programmes' mentioned above, primarily use in-kind benefits, ranging from MP3-players to crockery sets. Interestingly, while some schemes use incentives that are related to health and health-related behaviours, such as pharmacy vouchers (Greene, 2007), kitchen scales or bicycle helmets, ${ }^{9}$ many programmes offer incentives that have no apparent connection to health, e.g. when benefits were crockery sets or children's toys (in German bonus programmes) or even charity donations (in a programme piloted in the UK, see Carrell, 2008).

\section{$3 \quad$ 'Carrots' vs. 'sticks': a helpful distinction?}

Much of the debate about incentive schemes refers to the distinction between positive and negative incentives - or 'carrots' and 'sticks', or 'rewards' and 'penalties'. However, as I suggest in this section, drawing this distinction is not as straightforward as is often implied in the literature: there is no 'natural' way of distinguishing 'positive' from 'negative' incentives. Furthermore, when we consider different ways in which this distinction might be drawn, it becomes apparent that the provision of what, on the basis of these accounts, should be considered 'carrots', is not necessarily unproblematic.

In the literature, the distinction between 'carrots' and 'sticks', or positive and negative incentives, is common. For example, Jochelson suggests that positive incentives 'reward individuals directly for a desired behaviour or outcome' whereas negative incentives 'focus on the failure of an individual to adopt a desired behaviour and discipline the individual by withdrawing the reward' (Jochelson, 2007: 4). However, it is important to recognise that the line between policies that penalise and those that merely encourage cannot be drawn in a straightforward way (on this, see also Schmidt et al., 2009a). Both 'carrots' and 'sticks' effectively offer recipients the choice between two 'packages': those who adopt the behaviour in question will receive package $A$, those who do not engage in the behaviour, receive package $\mathrm{B}$; the relative size of the two packages will depend on whether the behaviour is to be encouraged or discouraged. ${ }^{10}$ This difficulty is reflected in the fact that specific incentive schemes have been described both as 'carrots' and as 'sticks'. Consider, for example, the West Virginia Medicaid policy that asked Medicaid recipients to sign a member agreement, committing them to cancelling appointments on time, getting regular check-ups, taking medications prescribed by their physician, etc. Those who complied with these requirements gained access to an 'enhanced' health care package; those who did not sign the agreement or failed to meet its requirements only had access to a 'basic' health care package, which excluded important services such as unlimited prescriptions and in-patient mental health services (Families USA, 2008a). This programme has been described both as rewarding its recipients ${ }^{11}$ and as penalising them. ${ }^{12}$ Similarly, after a US company raised employees' health insurance deductibles from $\$ 200$ to $\$ 2,200$ and then allowed those employees who met specific goals for blood pressure, cholesterol and body mass index to return to the previous level of deductible, the head of human resources explained that '[i]f they don't comply, they end up being penalized, if you will, but we refer to it as a Healthy Rewards program'. ${ }^{13}$ This illustrates that there is no clear structural difference between positive and negative incentives; what matters is the reference point we use to identify a particular incentive as a 
'reward' rather than a 'penalty'. ${ }^{14}$

Which reference point might we use to draw the line between sticks and carrots? Perhaps most important from the perspective of individuals is how a certain policy affects what is available to them, relative to previously available benefits. Incentive policies would then be 'carrots' to the extent that recipients gain access to services that were previously unavailable to them; where previously available services are made conditional upon individuals' meeting certain requirements, these would be seen as 'sticks'. On this account, the West Virginia Medicaid policy is most appropriately described as a penalty, since the 'basic plan' offered to recipients who do not sign or meet the requirements of the membership agreement does not include certain services that were previously covered in West Virginia's Medicaid programme (Families USA, 2008a).

This perspective is, perhaps, the most relevant to individuals' perception of whether they are offered a 'carrot' or being subjected to a 'stick', and it may also affect the impact of the policy. Psychologists' work suggests that individuals assess losses and gains of equal size differently, with losses being valued more negatively than gains are weighed positively (Kahneman and Tversky, 1979). These psychological effects are, of course, important; however, for the purposes of a normative assessment, this perspective gives undue weight to an individual's current share of (health care) resources. Consider, for example, someone starting from an unfairly large share of health care resources. This person may feel penalised if some of the services available to her are made conditional on certain requirements but, if her share is still much larger than that available to others, we would probably find it strange to say that she is subjected to a 'stick'. Thus, drawing the carrot-stick distinction on the basis of the perceptions of those affected by different policies may lead to implausible judgements about the nature of such policies.

A different reference point for drawing the distinction between 'sticks' and 'carrots' focuses on the importance of the services that are made conditional on individuals' meeting certain requirements. On this approach, we might think that when access to basic health care services and resources is made conditional on individuals' behaviour, this constitutes a 'stick', whereas the offer of non-basic services, conditional upon patients' meeting certain conditions, could be regarded as a 'carrot'. From this perspective, the West Virginia Medicaid policy again falls within the 'stick' category because it denies recipients some very basic health care services, such as unlimited prescriptions and in-patient mental health services. This perspective seems to motivate Daniels' (forthcoming) argument, which emphasises that justice requires that everyone be provided with 'a reasonable array of preventive and treatment services'. As Daniels notes, the West Virginia Medicaid package provided for those who do not meet the requirements of the member agreement 'is missing such important services as inpatient mental health'. Similarly, we may be particularly concerned about incentive schemes that alter price structures of health insurance plans to the point where they are affordable only to those who are able to meet a set of stipulated requirements. For example, US legislation on workplace wellness programmes allows insurers to require significantly higher contributions from employees who do not meet certain health status targets as stipulated by the health plan; these increases could potentially make health insurance prohibitively expensive for employees who do not meet these targets, thereby threatening their access to health care insurance (Schmidt et al., 2009b; Voigt and Schmidt, 2010; Families USA, 2008b). In comparison, schemes that offer patients MP3-players if they participate in, say, a weight loss programme, in addition to a decent health care package, seem fairly innocuous. However, while schemes that make elements of, or access to, a basic or reasonable health care package conditional upon recipients' being able to meet stated requirements are particularly problematic, there may be reasons of equality to be concerned even when non-basic services are at stake; similarly, when health care becomes 
significantly more expensive for some than it is for others, this raises concerns about equality even when coverage remains affordable for everyone.

Despite its frequent use in the debate about incentives, then, the distinction between sticks and carrots is problematic: it is far from clear how, exactly, this distinction is to be drawn, and even the provision of what we might consider 'carrots' can raise important concerns.

\section{$4 \quad$ Incentives and equality}

Discussions about the normative implications of health care policy frequently emphasise the importance of equality - or equity ${ }^{15}$ - as a desideratum in health care policy. While questions about equality feature in debates and decisions about social policy in many areas, it has been suggested that we are often particularly averse to inequality when it comes to health (Daniels, 2008). In health care, two aspects of equality feature prominently in the debate. First, questions about equality arise in the context of individuals' access to care: we ask, for example, whether co-payments required from patients may undermine equality of access to care as this payment may prevent lower income groups from obtaining treatment. A second aspect of equality has become prominent in recent debates, focusing on disparities in health outcomes. Health inequalities are common, to greater or lesser extent, in many countries, even when access to care is equal. Theoretical discussions assess the degree to which particular health inequalities are unjust (e.g. Daniels, 2008).

The reaction to incentive schemes is interesting in that these schemes have been both criticised for their likely negative impact on equality and welcomed as a possible strategy for improving equality in health outcomes. As an example of the former, consider Bishop and Brodkey's suggestion that the West Virginia Medicaid scheme is unfair for a number of reasons, one of them being that the policy 'asks the most vulnerable population to do more with less ability to accomplish what we ask of them' (Bishop \& Brodkey, 2006: 757). The West Virginia policy has been criticised widely along these lines. However, others have suggested that, when designed appropriately, incentive schemes could help reduce inequalities in health outcomes (Oliver, 2009, forthcoming; Cookson, 2008). The argument underlying this perspective is reasonable enough: health behaviours, such as nutrition, smoking and physical activity, make a significant contribution to social inequalities in health (e.g. Wanless, 2003; Marmot and Wilkinson, 2005; Khaw et al., 2008); policies that improve these behaviours among the disadvantaged could, therefore, make a significant contribution to greater equality in health.

Sections 5 and 6 provide a more systematic account of the ways in which incentive schemes may become problematic from the perspective of equality, and through which mechanisms they might be conducive to (health) equality. There are, of course, many different theories of equality. For the purposes of the present discussion, I will focus on two considerations that are important aspects of many of these theories and that have also featured prominently in the debate around equality in health and health care: equality of opportunity (or access) and equality of outcome.

Not all theories of equality will give weight to both of these considerations, and they may have different ways of conceptualising the relationship between them. For example, on some accounts of equality, equal access could justify unequal outcomes (e.g. Dworkin, 1981); others have suggested that unequal outcomes should be taken as an indication of unequal opportunities (Phillips, 2004). Empirically, there is a close link between unequal access and unequal outcomes, and concerns about incentive schemes that focus on access issues are closely linked to their impact on (health) inequalities: unequal access is likely to lead to unequal uptake, which in turn is likely to lead to unequal outcomes. However, these connections are not 'automatic': unequal access does not 
necessarily lead to unequal outcomes (e.g., if those for whom access is more difficult simply try harder) and outcome inequalities are not necessarily the result of unequal access (e.g., if the betteroff have easier access but do not find that the rewards on offer are worth their effort). As will become clearer throughout the discussion, it is helpful to consider questions around access separately from concerns about outcomes.

\section{$5 \quad$ Incentives and equality of access}

\subsection{Unequal access to rewards offered by incentive schemes}

From the perspective of equality, a first concern is that, in the case of some incentive schemes, it is harder for individuals who are worse off (either in terms of health or social advantage) to meet the condition to which the benefit is tied than it is for the better off. Many of the incentive schemes that have been introduced have focused on behaviours which those from less affluent backgrounds will find it harder to adopt. For example, in the US context, 'wellness incentives' are often tied to factors such as body mass index, cholesterol levels and smoking status. We know that there is a social gradient in these factors, which means that, right from the start, individuals from disadvantaged backgrounds are less likely to meet the stated goals than are more affluent individuals. Furthermore, social inequalities in living conditions will generally make it harder for those in disadvantaged groups to make progress towards these goals. We know, for example, that in low-income neighbourhoods, access to healthier food and exercise opportunities is restricted (e.g. Jetter and Cassady, 2006; Devine et al., 2006), that tobacco advertising is more prevalent in these neighbourhoods (e.g. Barbeau et al., 2005), etc. Similarly, keeping doctors' appointments - one of the conditions stipulated in the West Virginia Medicaid member agreement - is likely to be harder for people whose employment offers little flexibility over work hours and who must rely on public transport (Families USA, 2008b). Even schemes that tie rewards not to the achievement of certain health goals but to participation in health improvement schemes, such as smoking cessation or weight loss classes, can be susceptible to the unequal access problem. For example, low-income individuals may find that transport or child care costs can make it harder for them to participate than is the case for higher-income groups (Families USA, 2008b).

\subsection{Using incentive schemes to address barriers to access to health behaviours}

While many of the existing incentive schemes are problematic because they tie rewards to requirements that are not equally accessible to individuals from different socio-economic groups, it has been suggested that incentive schemes could be used to address barriers to specific beneficial health behaviours existing, in particular, for low-income groups (Jochelson, 2007). If incentive schemes can remove barriers to healthy behaviours among disadvantaged groups, they could make a contribution to the reduction of health inequalities. Cash incentives, in particular, have been used to address financial constraints. The low-paid jobs that disadvantaged people often depend on typically do not provide paid sick leave or allow flexibility for people to attend medical appointments (Families USA, 2008a). Providing cash for people who, for example, attend a screening appointment could help address this particular barrier; similarly, cash incentives can help make up for transportation or childcare costs (Post et al., 2006).

One further, possibly beneficial, aspect of incentive schemes was noted in a Scottish study on the effects of offering grocery vouchers to pregnant women for every week they did not smoke. The existence of rewards for abstaining from smoking gave participants an 'excuse to opt out of the social norm of smoking within their peer group' - without isolating them from that group (Ballard 
and Radlet, 2009: 151, emphasis omitted). Because the financial reward makes deviation from socially accepted behaviour 'legitimate', it can help address some of the social barriers and costs to behaviour change in disadvantaged groups.

However, because this strategy can work only under certain conditions, it faces significant limitations. First, our choice of benefit must be informed by the barriers disadvantaged individuals actually face when trying to adopt specific health behaviours. Many incentive schemes use rewards that are detached from the basic needs that disadvantaged individuals are trying to meet. Some of the in-kind benefits offered by some schemes, such as crockery sets or MP3-players, are less likely to meet this criterion than cash. A study found that the offer of gift certificates was not sufficient to ensure that patients attended medical appointments if they faced transport or financial problems (Laken and Ager, 1995). Furthermore, the rewards must be sufficiently large to address the financial barriers faced by low-income populations. For example, gym memberships and exercise classes can be so expensive that small incentive payments may be simply insufficient to make these affordable. In a study by Greene (2007), which considered the impact of offering cash incentives for Medicaid recipients to join gyms, one participant described trying to sign up for a 'Mommy and Me' yoga class: 'When I went to sign up for me and my son the lady told me it's $\$ 250$ for the sign up but then it's $\$ 40$ a month for the class. I said I can do Mommy \& Me in my home' (Greene, 2007: 12). Greene concludes that '[p]olicymakers should acknowledge that in some cases the barriers . . . may not be overcome by providing a small financial incentive' (Greene, 2007: 13). Similarly, cash incentives can help address financial barriers only if they are provided very soon after the cost is incurred; people on low incomes may have cash flow constraints and may therefore require immediate reimbursement.

Furthermore, using incentive schemes to address these barriers to beneficial health behaviours is a reasonable strategy only when the barriers to these behaviours can be both readily identified and addressed. As we saw in section 2, incentive schemes have been put in place to address a vast range of health behaviours. For many of these behaviours, there are multiple, complex reasons why disadvantaged populations find it harder to avoid health risks. For example, barriers to attending a doctor's appointment may include not just financial considerations but also lack of access to efficient transportation, language issues or low health literacy (Families USA, 2008a). Similarly, a complex picture emerges when we think about behaviours such as physical activity, smoking, diet, etc. Such behaviours are often 'woven into the fabric of poor people's social lives, operating as coping mechanisms and helping them survive poverty and its multiple humiliations' (Popay, 2008; see also Graham, 1993). It is far from clear that the prospect of a financial incentive alone could help address these issues. This is consistent with the empirical evidence suggesting that while incentive schemes could be an effective instrument for improving individuals' decisions about simple or distinct health behaviours, such as attendance of vaccination or screening programmes, they appear to be less effective with more complex behaviours that require a sustained effort over time, such as smoking, diet or physical activity (Jochelson, 2007; Cahill and Perera, 2008; Wilkinson, 2008; Greene, 2007; Sutherland et al., 2008). One study finds that (relatively large) financial incentives can improve cessation rates among smokers. However, the authors point out that the majority of their study population had high levels of education and income, and caution that their incentive scheme may not be equally effective with less affluent smokers (Volpp et al., 2009). The effectiveness of incentives with these complex health behaviours is, of course, crucial to the role that incentive schemes can play in addressing social inequalities in health: if incentive schemes cannot improve those behaviours that are, as the empirical evidence suggests, among the most significant contributors to social inequalities in health, this will, of course, limit the contribution 
these schemes can make to the reduction of health inequalities.

\section{Incentives and outcome inequalities}

The second broad concern of equality with respect to which incentive schemes must be evaluated concerns their effect on inequalities in outcomes. I begin by considering how the unequal uptake of incentive schemes could widen existing inequalities in both health and resources. While incentive schemes that are targeted towards disadvantaged populations may be able to avoid this problem, we must also be aware of the effects of incentives on individuals' decision-making processes. Finally, incentive schemes may convey certain 'messages' about health behaviour; the possible impact of these messages on the well-being of disadvantaged groups and their health behaviour must be taken into account.

\subsection{Inequalities in health and/or resources resulting from unequal uptake of incentive schemes}

The impact of incentive schemes on health inequalities is noted in the literature as an important criterion for the evaluation of these schemes (e.g. Le Grand and Srivastava, 2009). However, it is a familiar scenario in health care policy that public health initiatives provide greater benefits to the affluent than to the disadvantaged; similar problems may arise with incentive schemes. Furthermore, since incentive schemes offer tangible benefits for those complying with the stated requirements, we must also be concerned about the impact of such schemes on resource inequalities.

While the empirical literature does not give any conclusive answers about the impact of incentive schemes on inequalities, there is evidence that uptake of incentives tends to be unequal, with more affluent groups more likely to take advantage of benefits on offer (Bains et al., 2000; Braun et al., 2006; see also Schmidt, 2008). This leads to an increase in resource inequalities as higher income groups gain more of the benefits offered by incentive schemes than lower income groups. Whether or not the unequal uptake also increases health inequalities depends on whether or not those who obtain the benefit have to change their behaviour to do so. To the extent that those who participate in incentive schemes are already engaging in the specified health behaviour and would do so even without the benefit, incentive schemes affect resource inequalities but not health inequalities. ${ }^{16}$ To the extent that more affluent participants are actually improving health behaviours in order to obtain the benefit, both health and resource inequalities are increased.

\subsection{Targeting}

One strategy for preventing incentive schemes from widening health inequalities is to target such schemes at disadvantaged populations, offering them benefits that are not available to the wider population (Oliver, 2009). An example of such a targeted scheme is 'Opportunity NYC', a programme targeted at poor neighbourhoods in the New York City area to improve educational and health outcomes among this group. As part of this programme, low-income families are, for example, paid \$20 a month for maintaining health insurance for each parent and \$20 for maintaining it for their children. Payments of \$200 are made for each family member attending an annual medical check-up and, if the doctor recommends a follow-up visit, $\$ 100$ is paid for each family member attending within the recommended time frame. Families also receive $\$ 100$ for each family member who attends regular preventive dental check-ups (McColl, 2008).

This scheme is 'modeled' on the conditional cash transfer programmes that have been popular in 
low- and middle-income countries for some time. These schemes are generally targeted at poor populations, relying on explicit and sometimes also 'implicit' targeting mechanisms, where benefits are attached to behaviours that are not perceived as sufficiently attractive by wealthier individuals (e.g. sending one's children to public school). In some cases, the conditionality of the cash benefit is used not primarily to encourage behaviour change but as a less expensive and more efficient alternative to means-testing; tying the cash transfer to specific behaviours ensures that only the poor will try to gain access to the benefit while relieving resource-poor countries of more expensive ways of identifying the needy (Das et al., 2005).

Incentive schemes that target poor populations in this way help address concerns about health inequalities because the benefits provided by these schemes are available only to the targeted group; if the targeting works, only individuals who are identified as disadvantaged gain access to the incentive in question. Such incentive schemes, if successful, can improve health and health behaviours among the disadvantaged without offering resources to the better off, thus helping to reduce both health and resource inequalities. Importantly, such schemes do, in a sense, involve unequal access (some people do not have access to the scheme at all), but this time the inequality in access is tilted in favour of the disadvantaged specifically so as to improve their health outcomes.

\subsection{Incentives and individual decision-making}

Incentives 'work' by influencing individuals' decision-making towards meeting the requirement rewarded by the incentive. In trying to evaluate the effects of incentives on individual decisionmaking, two questions arise. First, do incentives have a positive or a negative impact on individual decision-making? Second, since we are interested in inequalities that might arise as a result of incentive schemes, we must ask whether any such impact is stronger among some groups than it is among others in a way that might create inequalities (or exacerbate existing ones) or reduce them.

With respect to the effect that incentives have on the 'quality' of individuals' decisions, arguments can be made on both sides. On the one hand, we often find it difficult to adopt behaviours that are beneficial to our health because the health benefits may not materialise until far in the future. There are, however, often very immediate benefits to unhealthy behaviours. Offering an incentive that 'rewards' beneficial behaviours right now could help address this problem. Furthermore, when incentives tie immediate benefits (or costs) to certain health behaviours, this may facilitate individuals' making behaviour changes that they themselves endorse but find difficult to adopt in the absence of short-term benefits (Le Grand and Srivastava, 2009). On the other hand, incentive schemes may introduce financial considerations into decisions that, arguably, should be based on medical and health considerations alone, possibly leading to decisions that are, in fact, worse for an individual's health than the decisions that would have been made in the absence of the incentive (Marteau et al., 2009).

In addition to an assessment of the beneficial or detrimental impact of incentives on individual decision-making, we must also ask whether the size of these effects varies for people from different socioeconomic backgrounds. It has been suggested that incentive schemes would lead to greater improvements among lower-income groups because, for them, a specified cash payment is 'worth' more than it is for more affluent groups (Dudley et al., 2007). However, as I noted in the previous section, the empirical evidence on existing incentive schemes points to the opposite effect, i.e., the uptake of incentives is greater among more affluent groups.

Consider two policies that help illustrate the problems discussed here. In the first policy, which is used in Germany, sickness funds can offer cash rewards to enrolees who were not hospitalised or 
prescribed medication for the previous year. In this scenario, it seems plausible that the incentive will have a negative effect on patients' decision-making as they may decide, for financial reasons, to delay visits to the doctor or avoid being referred to a hospital, risking negative health consequences as a result. Furthermore, other things being equal, the financial incentive is likely to have a greater effect on the decision-making process of individuals in lower-income groups, for whom the reimbursements offered are more significant.

A more ambiguous picture emerges from schemes that tie incentives to patients' compliance with doctor's advice and prescribed medications (e.g. the West Virginia's Medicaid member agreement; see Greene, 2007). When patients want to take a certain medication and non-compliance is merely the result of forgetfulness, an incentive could have a positive effect in helping individuals take their medications regularly. However, decisions about whether or not to take medication prescribed by a physician involve patients' weighing possible costs and benefits. Some medications relieve symptoms but have significant side effects, and patients will want to make decisions about such medication on the basis of their particular situation and preferences. In this scenario, the introduction of an incentive may lead patients to make decisions, not on the basis of their health, but with a view to obtaining the benefits on offer. ${ }^{17}$ Since a financial incentive may be less of a consideration for more affluent patients, lower-income patients may be more likely to end up making decisions that they do not perceive to be in their best interest.

\subsection{The 'message' of incentive schemes and its impact on well-being and health behaviour}

A further aspect of incentive schemes that needs to be considered is the broader 'message' such schemes convey to potential participants, and how this might affect their well-being and/or health behaviours. On the one hand, incentive schemes may communicate that specific health behaviours are important. Consider, for example, a study by Marcus et al. (1992), in which bus passes were posted to low-income women who had had abnormal pap smears to encourage return for a followup visit. They found that this increased return for follow-ups even though only about a third of the women who had received the bus passes actually used them. They suggest that the incentive may have communicated to patients that the follow-up visit was important for their health. One participant noted, 'This must be important, otherwise they would not send me a bus pass' (Marcus et al., 1992: 227). The survey also suggested that the provision of bus passes was taken as an indication of the clinic's concern for patients' health and well-being. While the policy in this study is not an incentive scheme in the strict sense, incentive policies may be able to convey similar messages to eligible individuals, with a positive impact on their health behaviours. Furthermore, it has also been suggested that emphasising the importance of individual behaviour could help address feelings of resignation and fatalism among disadvantaged groups, helping them realise that despite structural constraints - there is scope for individual actions that can improve health (Schmidt, 2009). These effects may have beneficial implications for individuals' well-being and may also improve their health behaviours.

On the other hand, incentive policies are often framed within a larger discourse about individual choice and patient responsibility. ${ }^{18}$ This may trivialise the structural barriers that prevent individuals from adopting the behaviours these schemes are trying to encourage. When the barriers and structural factors constraining individuals' choices are made to appear insignificant, this could contribute to a sense of personal failure when health behaviours cannot be adopted or maintained. This may induce feelings of guilt, shame, frustration or self-blame (Guttman and Salmon, 2004; Guttman and Ressler, 2001), and these feelings may also become an obstacle to the improvement of health behaviours (Guttman and Ressler, 2001: 121). A focus on individual behaviour rather than 
the wider social determinants of health as part of a strategy for the reduction of health inequalities may also affect public discourse in a way that stigmatises those who fail to engage in behaviours recognised as healthy. The appeal to individuals to 'take responsibility' for their health may also implicitly label as 'irresponsible' those who fail to do so (see also Popay, 2008).

How exactly incentive schemes pan out in terms of the messages they convey, and what impact these messages have on individuals' well-being and health behaviours, is an empirical question. It may be possible to design incentive schemes to avoid the negative effects anticipated in the literature. However, in considering and evaluating the introduction of incentive schemes, these effects should be an important consideration.

\section{Evaluating incentive schemes: caveats and trade-offs}

The previous two sections raised a number of equality-based concerns about incentive schemes. How should these concerns feed into an overall evaluation of incentive schemes? This section draws attention to three important considerations. First, incentive schemes might involve trade-offs between different considerations of equality. Second, the effect of incentives on inequality must be weighed against other considerations, such as overall health improvements to which these schemes can lead. Finally, if incentive schemes are to be a strategy for the reduction of health inequalities, their efficacy at achieving this goal must be compared to alternative policy strategies.

\subsection{Trade-offs between different equality-based considerations}

The considerations outlined in sections 5 and 6 need not go hand-in-hand. For example, it may turn out that policies that create or heighten existing stigma around health-risky behaviours are highly successful at reducing these behaviours among disadvantaged groups. This means that we may be facing difficult trade-offs when considering how specific schemes affect equality, often involving trade-offs in different 'metrics' of equality.

Similar 'intra-equality' trade-offs can arise with policies that aim to address disadvantage among children and young adults, but do so by imposing burdens on their (disadvantaged) parents. Conditional cash transfers used in developing countries often offer incentives to parents if they engage in behaviours that are seen as conducive to their children's health (Forde and Zeuner, 2009). Similarly, a policy recently implemented in Georgia (US) reduced parents' access to welfare payments unless they could provide evidence that their children had received all age-appropriate vaccinations (Kerpelman et al., 2000). Such schemes impose additional - and likely unfair burdens on already disadvantaged parents but we may decide that these burdens are outweighed if the benefits the schemes provide to children are sufficiently large. It is crucial that these trade-offs, and the costs associated with the achievement of particular goals, be acknowledged and explicitly evaluated.

\subsection{Trade-offs between equality and other considerations}

There may also be trade-offs between equality and other objectives. In particular, it may turn out that incentive schemes are a highly effective way of improving population health even though they exacerbate existing health inequalities. For example, an incentive scheme that can help smokers quit but is more successful among higher-income than disadvantaged smokers would significantly improve health outcomes, albeit less so among lower-income groups (see also Daniels, 2008, for discussion of a more general case of this). The health improvement must then be weighed against the loss in health equality, and we may decide that the increase in health inequality is a price worth 
paying for significant increases in population health (Mechanic, 2002). Adjudicating between different goals of this kind is a vexing problem in philosophy and, in fact, this trade-off may not be best left to philosophers: Daniels suggests that such choices be made through a public, deliberative process to ensure that a reasonable and legitimate decision is reached (Daniels and Sabin, 2008; Daniels, 2008). However these decisions are eventually made, it is important that in evaluating these possible trade-offs, those aspects of incentive schemes that raise problems of inequality and unfairness are fully acknowledged and weighed against the possible benefits of such programmes.

\subsection{Are incentive schemes more effective at reducing health inequalities than alternative policies?}

If incentive schemes are to be a tool for addressing social inequalities in health, an important question we need to ask is whether these schemes are more effective than alternative policy tools in achieving this outcome. In particular, we must ask whether incentive schemes are more effective than policies that aim to address directly the barriers to 'healthy' behaviours, especially those existing among disadvantaged groups. This should include measures that redistribute resources to low-income groups without the imposition of conditionality requirements but also policies that address the physical environment of deprived communities. For example, Tester and Baker (2009) report that the improvement of park spaces in low-income neighbourhoods increased physical activity among residents of the area. Our assessment of the effectiveness of incentive schemes must also be sensitive to the costs involved in administering such programmes, monitoring individuals' compliance with specific conditionality requirements, informing eligible individuals about the scheme, etc. (E.g., Redmond et al., 2007, note that the administrative costs associated with the Florida Medicaid incentive scheme were $\$ 1.1 \mathrm{~m}$.) Schemes that are targeted towards specific populations may also accrue additional costs in identifying eligible individuals. How effectively incentive schemes can reduce health inequalities and how they compare to other possible strategies to achieve this goal is, of course, an empirical question, but if incentive schemes are to be used as an instrument of equality, then it is crucial that they can achieve this objective at least as effectively as other policy approaches.

\section{Conclusion}

Incentives have become an increasingly popular strategy to bring about positive changes in health behaviour. The framework of incentive schemes is very broad and, as the survey of existing and proposed schemes in section 2 showed, they can be designed in very different ways; our assessment of incentive schemes must be sufficiently sensitive to these differences. In this paper, I suggested that the distinction between 'carrots' and 'sticks', or 'rewards' and 'penalties', is of only limited benefit in assessing these schemes. I identified a number of criteria relevant from the perspective of equality. These criteria could be helpful both in evaluating the 'equality impact' of incentive schemes and in designing schemes in a manner that is sensitive to considerations of equality. I also commented on how these considerations should feed into an overall evaluation of incentive schemes as a tool for improving population health. At the same time, the paper raised a number of questions that can be answered only on the basis of empirical evidence; the paper identified some of the empirical questions we need to ask to determine whether incentive schemes are consistent with considerations of equality or even a policy tool for the reduction of social inequalities in health.

\section{References}

Bains, N., Pickett, W., Laundry, B. and Mercredy, D. (2000), 'Predictors of smoking cessation in an 
incentive-based community intervention', Chronic Diseases in Canada 21(2): 54-61.

Ballard, P. and Radlet, A. (2009), 'Give it up for baby: a smoking cessation intervention for pregnant women in Scotland', Cases in Public Health Communication \& Marketing 3: 147160.

Barbeau, E., Wolin, K., Naumova, E. and Balbach, E. (2005), 'Tobacco advertising in communities: associations with race and class', Preventive Medicine 40(1): 16-22.

Bishop, G. and Brodkey, A. (2006), 'Personal responsibility and physician responsibility - West Virginia's Medicaid Plan', New England Journal of Medicine 355(8): 756-758.

Braun, B., Reiners, H., Rosenwirth, M. and Schlette, S. (2006), Anreize zur Verhaltenssteuerung im Gesundheitswesen: Effekte bei Versicherten und Leistungsanbietern. Gütersloh: Bertelsmann Stiftung.

Cahill, K. and Perera, R. (2008), 'Competitions and incentives for smoking cessation', Cochrane Database of Systematic Reviews 3, Art. No.: CD004307, DOI: 10.1002/14651858.CD004307.pub3.

Carrell, S. (2008), 'Pupils earn just reward for healthy eating', The Guardian, 3 November.

Claassen, D. (2007), 'Financial incentives for antipsychotic depot medication: ethical issues', Journal of Medical Ethics 33(4): 189-193.

Claassen, D., Fakhoury, W., Ford, R. and Priebe, S. (2007), 'Money for medication: financial incentives to improve medication adherence in assertive outreach', Psychiatric Bulletin 31(1): $4-7$.

Cookson, R. (2008), 'Should disadvantaged people be paid to take care of their health? Yes', British Medical Journal 337: a589.

Daniels, N. (2008), Just Health: Meeting Health Needs Fairly. Cambridge: Cambridge University Press.

. (forthcoming), 'Individual and social responsibility for health', in C. Knight and Z. Stemplowska (eds.), Distributive Justice and Responsibility. Oxford and New York: Oxford University Press.

Daniels, N. and Sabin, J. (2008), Setting Limits Fairly: Learning to Share Resources for Health. Second Edition. New York: Oxford University Press.

Das, J., Do, Q. and Ozler, B. (2005), 'Reassessing conditional cash transfer programs', The World Bank Research Observer 20(1): 57-80.

Devine, C. M., Jastran, M., Jabs, J., Wethington, E., Farell, T. J. and Bisogni, C. A. (2006), "'A lot of sacrifices": work-family spillover and the food choice coping strategies of low-wage employed parents', Social Science and Medicine 63(10): 2591-2603.

Dudley, R., Tseng, C., Bozic, K., Smith, W. and Luft, H., 2007, 'Consumer financial incentives: A decision guide for purchasers'. Rockville, MD, Agency for Healthcare Research and Quality, AHRQ Publication No. 07(08)-0059.

Dworkin, R. (1981), 'What is equality? Part 2: Equality of resources', Philosophy \& Public Affairs 10(4): 283-345.

Eckholm, E. (2006), 'Medicaid plan prods patients toward health', New York Times, 1 December.

Families USA (2008a), Mountain Health Choices: An Unhealthy Choice for West Virginians [accessed 4 June 2009]. Available from http://www.familiesusa.org/assets/pdfs/state-planamendments/wv-mountain-health-choices.pdf. (2008b), Reward/Penalty
$\begin{aligned} & \text { [accessed } \\ & \text { http://www.familiesusa.org/assets/pdfs/wellness-plans.pdf. }\end{aligned}$

Federal Register. (2006), 'Nondiscrimination and wellness programs in health coverage in the group 
market; final rules', Federal Register 71(239): 75014-75055, December 13.

Florida Agency for Health Care Administration (2005), Florida Medicaid Reform Application for 1115 Research Demonstration and Waiver, October 2005 [accessed 15 February 2010]. Available http://ahca.myflorida.com/medicaid/medicaid reform/waiver/pdfs/medicaid reform waiver final 101905.pdf.

Forde, I. and Zeuner, D. (2009), 'Financial incentives to promote social mobility', British Medical Journal 339: b3219.

Graham, H. (1993), When Life's a Drag: Women, Smoking and Disadvantage. London: Department of Health.

Greene, J., 2007, 'Medicaid efforts to incentivize healthy behaviors', Center for Health Care Strategies, Inc.

Guttman, N. and Ressler, W. (2001), 'On being responsible: ethical issues in appeals to personal responsibility in health campaigns', Journal of Health Communication 6(2): 117-136.

Guttman, N. and Salmon, C. T. (2004), 'Guilt, fear, stigma and knowledge gaps: ethical issues in public health communication interventions', Bioethics 18(6): 531-552.

Hand, L. (2009), 'Carrots and sticks: employers prod workers to adopt behaviors to improve health', Harvard Public Health Review Winter 2009: 4-9.

Hilzenrath, D. (2009), 'Wellness incentives could create health-care loophole', Washington Post, 16 October.

Jetter, K. and Cassady, D. (2006), 'The availability and cost of healthier food alternatives', American Journal of Preventive Medicine 30(1): 38-44.

Jochelson, K. (2007), Paying the Patient: Improving Health Using Financial Incentives. London: King's Fund.

Kahneman, D. and Tversky, A. (1979), 'Prospect theory: An analysis of decision under risk', Econometrica 47(2): 263-291.

Kerpelman, L., Connell, D. and Gunn, W. (2000), 'Effect of a monetary sanction on immunization rates of recipients of Aid to Families with Dependent Children', JAMA 284(1): 53-59.

Khaw, K.-T., Wareham, N., Bingham, S., Welch, A., Luben, R. and Day, N. (2008), 'Combined impact of health behaviours and mortality in men and women: The EPIC-Norfolk prospective population study', PLoS Medicine 5(1): e12.

Lagarde, M., Haines, A. and Palmer, N. (2007), 'Conditional Cash Transfers for improving uptake of health interventions in low- and middle-income countries', JAMA 298(16): 1900-1910.

Laken, M. and Ager, J. (1995), 'Using incentives to increase participation in prenatal care', Obstetrics \& Gynecology 85(3): 326-329.

Le Grand, J. and Srivastava, D. (2009), Incentives for Prevention. London: Health England.

Marcus, A. C., Crane, L. A., Kaplan, C. P., Reading, A. E., Savage, E., Gunning, J., Bernstein, G. and Berek, J. S. (1992), 'Improving adherence to screening follow-up among women with abnormal pap smears: results from a large clinic-based trial of three intervention strategies', Medical Care 30(3): 216-230.

Marmot, M. and Wilkinson, R. G., eds. 2005. Social Determinants of Health, 2nd ed. Oxford: Oxford University Press.

Marteau, T. M., Ashcroft, R. E. and Oliver, A. (2009), 'Using financial incentives to achieve healthy behaviour', British Medical Journal 338: b1415.

McColl, K. (2008), 'New York's road to health', British Medical Journal 337: a673.

Mechanic, D. (2002), 'Disadvantage, inequality, and social policy', Health Affairs 21(2): 48-59.

Mello, M. and Rosenthal, M. (2008), 'Wellness programs and lifestyle discrimination - the legal 
limits', New England Journal of Medicine 359(2): 192-199.

Okie, S. (2007), 'The employer as health coach', New England Journal of Medicine 357(15): 1465.

Oliver, A. (2009), 'Can financial incentives improve health equity?', British Medical Journal 339: 705-706.

. (forthcoming), 'Reflections on the development of health inequalities policy in the United Kingdom', Health Care Analysis.

Phillips, A. (2004), 'Defending equality of outcome', Journal of Political Philosophy 12(1): 1-19.

Popay, J. (2008), 'Should disadvantaged people be paid to take care of their health? No', British Medical Journal 337(7662): a594.

Post, E., Cruz, M. and Harman, J. (2006), 'Incentive payments for attendance at appointments for depression among low-income African Americans', Psychiatric Services 57(3): 414-416.

Redmond, P., Solomon, J. and Lin, M., 2007, 'Can incentives for health behavior improve health and hold down Medicaid costs?'. Washington, DC, Center on Budget and Policy Priorities.

Schmidt, H. (2007), 'Personal responsibility for health - developments under the German Healthcare Reform 2007', European Journal of Health Law 14(3): 241-250.

. (2008), 'Bonuses as incentives and rewards for health responsibility: a good thing?', Journal of Medicine \& Philosophy 33(3): 198-220.

. (2009), 'Personal responsibility in the NHS Constitution and the social determinants of health approach: competitive or complementary?', Health Economics, Policy and Law 4(2): 129-138.

Schmidt, H., Gerber, A. and Stock, S. (2009a), 'What can we learn from German health incentive schemes?', British Medical Journal 339: 725-728.

Schmidt, H., Voigt, K. and Wikler, D. (2009b), 'Carrots, sticks, and health care reform - problems with wellness incentives', New England Journal of Medicine, published online 30 December.

Schnee, M. (2007), 'Neue Versorgungs- und Versicherungsformen in der GKV: Wer kennt sie und wer nutzt sie?', Gesundheitsmonitor 2: 1-9.

Sindelar, J. (2008), 'Paying for performance: the power of incentives over habits', Health Economics 17(4): 449-451.

Sutherland, K., Leatherman, S. and Christianson, J. (2008), Paying the Patient: Does it Work? A Review of Patient-targeted Incentives. London: The Health Foundation.

Tester, J. and Baker, R. (2009), 'Making the playfields even: Evaluating the impact of an environmental intervention on park use and physical activity', Preventive Medicine 48(4): 316-320.

Voigt, K. and Schmidt, H. (2010), 'Wellness programs: a threat to fairness and affordable care', Hastings Center Health Care Cost Monitor, 13 January. Available at $\mathrm{http}$ //healthcarecostmonitor.thehastingscenter.org/kristinvoigt/wellness-programs-a-threatto-fairness-and-affordable-care/.

Volpp, K. G., Troxel, A. B., Pauly, M. V., Glick, H. A., Puig, A., Asch, D. A., Galvin, R., Zhu, J., Wan, F., DeGuzman, J., Corbett, E., Weiner, J. and Audrain-McGovern, J. (2009), 'A randomized, controlled trial of financial incentives for smoking cessation', New England Journal of Medicine 360(7): 699-709.

Wanless, D. (2003), Securing Good Health for the Whole Population: Population Health Trends. London: HMSO.

Warner, K. and Murt, H. (1984), 'Economic incentives for health', Annual Review of Public Health 5(1): 107-133.

Wikler, D. (1978), 'Persuasion and coercion for health: ethical issues in government efforts to 
change life-styles', Millbank Memorial Fund Quarterly 56(3): 303-327.

Wilkinson, E. (2008), 'Can you pay people to be healthy?', Lancet 371(9621): 1325-1326.

${ }^{1}$ E.g. Bishop and Brodkey, 2006.

${ }^{2}$ Oliver, 2009, forthcoming; Cookson, 2008; Sindelar, 2008.

${ }^{3}$ Daniels, 2008, ch. 11; forthcoming; Schmidt, 2008; Popay, 2008.

${ }^{4}$ See Hand, 2009; Okie, 2007; Schmidt et al., 2009b. For a discussion of the legal framework around such initiatives, see Mello and Rosenthal, 2008.

${ }^{5}$ E.g. http://www.barmer.de/barmer/web/Portale/Versichertenportal/Leistungen_20und_20Beitr_C3_A 4ge/Ihre_20Vorteile_20bei_20der_20Barmer/Bonusprogramm/So_20einfach_20 gehts/So_20einf ach_20gehts.html, http://www.tk-online.de/tk/leistungen-und-services/bonusprogramm/dasprogramm-2009/38502 (both accessed 2 June, 2009). See also Schmidt, 2007; Schmidt et al., 2009a for discussion of these schemes.

${ }^{6}$ See http://nhsweightlosstrial.com (accessed 1 September 2009).

${ }^{7}$ See, for example, http://www.barmer.de/barmer/web/Portale/Versichertenportal/Leistungen_20und_20Beitr_C3_A 4ge/Exzellent_20in_20den_20Extras/Bonusprogramm/So_20sammeln_20Sie_20Punkte/Punkte_ 20sammeln.html?w-cm=RightColumn_t203210 and http://www.tk-online.de/tk/leistungen-undservices/bonusprogramm/massnahmen/140978?view=renderTabelle\&tableindex $=3$

${ }^{8}$ See http://www.aok.de/berl/rd/123941.htm.

${ }^{9}$ See, for example, http://www.tk-online.de/tk/leistungen-undservices/bonusprogramm/massnahmen/140978? view=renderTabelle\&tableindex $=3$

${ }^{10}$ See Wikler, 1978: 330, for a similar example.

${ }^{11}$ By Nancy Atkins, cited in Eckholm, 2006.

${ }^{12}$ Families USA, 2008a.

${ }^{13}$ Cited in Hilzenrath, 2009.

${ }^{14}$ See also Warner and Murt, 1984: 108.

${ }^{15}$ The philosophical literature generally uses the terms 'equality' and 'inequality', where inequality includes both fair and unfair inequalities. Much of the work around health uses the terms 'equity' and 'inequity', with 'inequity' denoting only those disparities that are unfair. In this paper, I adopt the former terminology.

${ }^{16}$ Data from Germany suggests that this might be the case there; see Schnee, 2007.

${ }^{17}$ Another policy that might be mentioned in this context is a scheme piloted in the UK, which 
offers cash to patients for obtaining anti-psychotic depot medication (Claassen et al., 2007; Claassen, 2007). Just as the policies discussed above, this scheme may help patients comply but it could also interfere with patients' decisions about which medications to take. The fact that this policy is targeted at patients with mental health problems that may also affect the decisionmaking process raises additional problems.

${ }^{18}$ See, for example, Florida Agency for Health Care Administration, 2005. 